\title{
Impacts of Vegetation Cover on Surface-Groundwater Flows and Solute Interactions in a Semi-Arid Saline Floodplain: A Case Study of the Lower Murray River, Australia
}

\author{
Sina Alaghmand • Simon Beecham • Ali Hassanli
}

Received: 22 November 2013 / Accepted: 7 December 2013 /Published online: 24 April 2014

(C) Springer International Publishing Switzerland 2014

\begin{abstract}
Despite many studies on floodplain vegetation, there is limited quantitative understanding of the role of vegetation in surface water (SW) and groundwater (GW) interactions through processes such as evapotranspiration. Moreover, most of the investigations that have been undertaken on SW-GW interactions consider 1D or 2D model set-ups. In addition, most of the modelling studies in this research area have only included water but not solute transport. This paper presents the results of a study on the potential impacts of vegetation cover on the interaction of a river and a saline semi-arid floodplain aquifer using a 3D physically-based fully integrated numerical model. In this regard the following three scenarios were defined: current vegetation cover (calibration model), deep-rooted vegetation cover and shallow-rooted vegetation cover. Clark's Floodplain, located on the Lower Murray River in South Australia was selected as the study site. The results show that deep-rooted vegetation cover may maintain relatively deeper groundwater levels and a less saline floodplain aquifer. Also, it is shown that in the shallow-rooted scenario, most of the ET component belongs to the evaporation process due to shallower groundwater. On the other hand, the deep-rooted model includes groundwater uptake largely via a transpiration process, and consequently keeps the groundwater levels below the evaporation depth. Overall, in semi-arid areas, the vegetation cover type can have significant impacts on the flow and solute interaction dynamics of a river and a floodplain aquifer due to the influence of ET as a dominant hydrological driver.
\end{abstract}

Keywords Floodplain vegetation - Semi-arid floodplain · Surface-groundwater interactions · HydroGeoSphere $\cdot$ Lower Murray River

S. Alaghmand $(\square) \cdot$ S. Beecham $\cdot$ A. Hassanli

Centre for Water Management and Reuse, School of Natural and Built Environments,

University of South Australia, Mawson Lakes, Adelaide, SA 5095, Australia

e-mail: sina.alaghmand@mymail.unisa.edu.au

A. Hassanli

College of Agriculture, Shiraz University, Shiraz, Iran 


\section{Introduction}

The interaction between surface water (SW) and groundwater (GW) is strongly controlled by the relative heads and these can vary significantly over a period of time (Rosenberry and Winter 1997). For instance, changes in SW-GW interactions will occur when there are modifications to the native vegetation due to dry-land agriculture, irrigation, forestry, urban development (Allison et al. 1990; Doble et al. 2006). For instance, the processes leading to floodplain salinization after the clearance of native vegetation for agricultural practices is shown in Fig. 1. Trees, particularly those with deep roots, behave like groundwater pumps, and play a key role in the catchment water balance (Banks et al. 2011; Butler et al. 2007; Loheide et al. 2005). On the other hand, evapotranspiration (ET) may create an unsaturated storage zone for salt in some areas of the floodplain, particularly where deep rooted vegetation types exist, or for certain times or seasons of the year. During overbank flow and/or extreme rainfall events, these unsaturated zones containing the stored salt can become saturated, which may cause salt leaching and groundwater salinization. This shows the importance of ET on the dynamics of flow and solute in a river-floodplain interaction in arid/semi-arid areas. Evans (2011) concluded that groundwater under a floodplain is often more saline than the regional (input) groundwater. This infers that there is a salt concentration process operating under the floodplain. Holland et al. (2009) showed that salinization associated with groundwater discharge via ET is the principal process influencing floodplain vegetation health, particularly in arid and semi-arid regions. For instance, in the Lower Murray River in South Australia, there are natural inflows of saline regional groundwater to the floodplains. The raised groundwater level beneath the floodplain has led to increased rates of groundwater evapotranspiration. Because the groundwater is naturally saline, the increased ET results in floodplain salinization, which consequently affects the health of floodplain vegetation. In fact, groundwater flow into the floodplain is discharged mainly as ET when the water table is within the evapotranspiration extinction depth (Holland et al. 2009). Doble et al. (2006) demonstrated that long-term patterns of net groundwater discharge are dependent on vegetation distribution, elevation, soil type and river geometry. Bornman et al. (2004) showed that the distribution and health of vegetation in a floodplain depends on the depth to the water table and the salinity of the groundwater. Also, anthropogenic changes to flooding regimes in highly variable arid catchments have a critical effect on floodplain vegetation (Alexander and Dunton 2006; Capon 2005; Mensforth and Walker 1996). Indeed, the total exchange flux between a river and the adjacent floodplain aquifer includes the following components: (1) natural exchange flux due to river stage fluctuations; (2) exchange flux due to groundwater extraction/injection; (3) exchange flux due to a change in recharge rates (e.g., change in landuse); and (4) exchange flux due to changes in ET patterns. It seems that ET is a significant mechanism in shallow aquifers, particularly in arid and semi-arid regions where overbank flows and rainfall recharge are unlikely to occur (Rassam 2002; Rassam 2011).

Despite long-term studies on floodplain vegetation, there is limited quantitative understanding of the role of vegetation (i.e., ET) on the SW-GW interactions (Alaghmand et al. 2013b). It is also unclear how land clearance or revegetation affects the dynamic of flow and solute (Banks et al. 2011). Moreover, most of the investigations in the context of SW-GW interactions consider 1D or $2 \mathrm{D}$ model set-ups. To establish a more realistic representation of the natural environment, 3D modelling is important. Some examples are the spatial distribution of salt accumulated in a floodplain/wetland, the impact of variable vegetation cover on SW-GW interactions and ET distribution, and the state of SW and GW connections along a river induced by ET, pumping, flooding, and other factors (Banks et al. 2011). Banks et al. (2011) studied the impacts of floodplain vegetation cover on the state of connection of SW and GW. They suggested that in addition to the well-known influences of physical variables, such as hydraulic conductivity and topography, the 


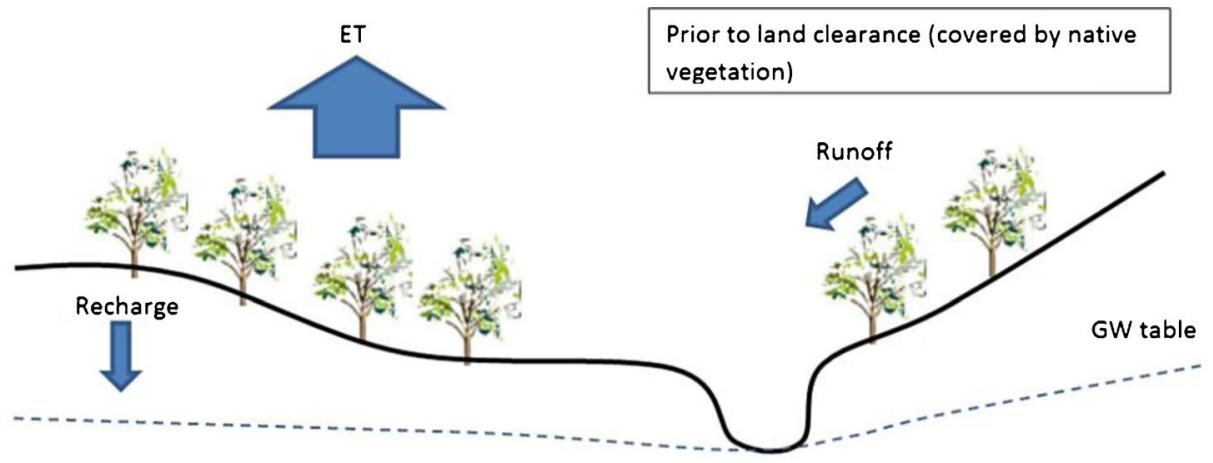

Recharge from irrigation

After land clearance (covered by shallow-

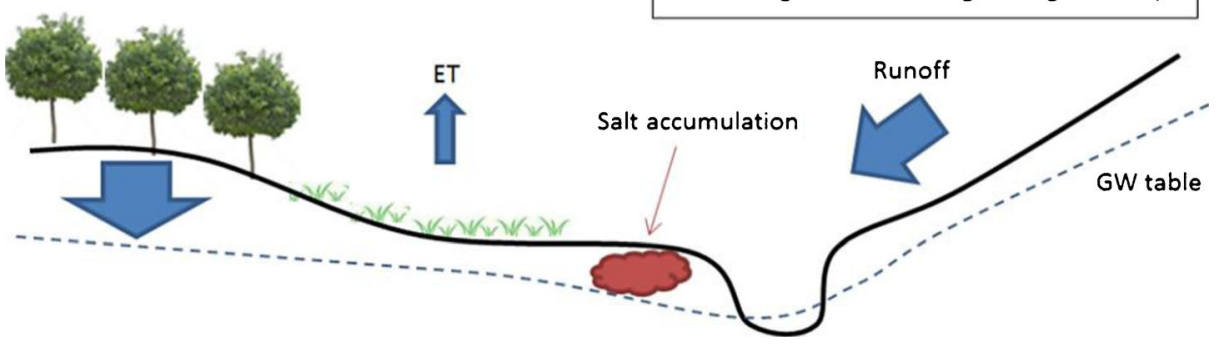

Fig. 1 Schematic diagram of processes leading to floodplain salinization after the clearance of native vegetation for agricultural practices (adapted from Leblanc et al. 2012)

effects of vegetation need to be carefully considered when investigating SW-GW interactions. They recommended further work to be carried out in 3D to explore the effects of ET on river and floodplain interactions as function of vegetation cover. Most other modelling studies in this research area have only included water but not solute dynamics.

This study aims to explore the following hypothesis: can vegetation cover significantly influence the dynamics of flow and solute in the context of a river and a semi-arid saline floodplain interaction? This is tested in this study through the following three scenarios: current vegetation (mix of deep rooted and shallow rooted vegetation); coverage by only deep rooted vegetation types, such as Eucalyptus trees; and coverage by only shallow rooted vegetation types such as grass. The current vegetation scenario is considered as the base case scenario and is developed and calibrated using observed data. The other two scenarios are theoretically developed and compared with the base scenario. The impacts of vegetation cover on solute and water balances and the state of connection of SW-GW are investigated using a $3 \mathrm{D}$ fully-integrated numerical model.

\section{Material and Methods}

A total of three scenarios were defined to investigate the impacts of floodplain vegetation cover on a river and a saline semi-arid floodplain aquifer interaction. In fact, the defined scenarios are differentiated by modifying vegetation distribution and ET properties of each 
vegetation type $(0.5 \mathrm{~m}$ root depth value is used for grass and $5 \mathrm{~m}$ root depth for Eucalyptus coverage). It is worth noting that floodplain groundwater at the study site is influenced by groundwater extraction through a series of production wells that form part of the Bookpurnong Salt Interception Scheme (SIS). These wells aim to alter hydraulic gradients and intercept the movement of saline groundwater from the highlands to the alluvium and the river. Two of the SIS production wells ( $32 \mathrm{~F}$ and $34 \mathrm{~F}$ ) are located in the study site and are included in the model, as shown in Fig. 2.

\subsection{Governing Equations}

The HydroGeoSphere (HGS) model provides a rigorous simulation capability that combines fully-integrated hydrologic/water quality/subsurface and transport capabilities with a welltested set of user interface tools (Therrien et al. 2010). HGS requires pre- and post-processor tools in order to handle input preparation and visualization of the outputs. In this study, the Groundwater Modelling System (GMS) (AquaVeo 2011) was used as a pre-processor to generate the input grid domain and as a post-processor to visualize the model results.

ET is calculated as a combination of transpiration and evaporation. Transpiration from vegetation occurs within the root zone of the subsurface and is a function of the leaf area index (LAI), nodal water (moisture) content $(\theta)$ and a root distribution function (RDF) over a prescribed extinction depth (Alaghmand et al. 2013a). Water content is simulated as saturation because it is more stable and always varies between 0 and 1 , while in reality moisture content varies from 0 to a value equal to the porosity. The rate of transpiration $\left(T_{p}\right)$ is estimated using the following relationships (Kristensen and Jensen 1975):

$$
T_{p}=f_{1}(\mathrm{LAI}) f_{2}(\theta) \operatorname{RDF}\left[E_{p}-E_{c a n}\right]
$$

where $E_{p}$ is the reference potential evapotranspiration which may be derived from pan measurements or computed from vegetation and climatic factors such as temperature and humidity, and $E_{c a n}$ is the tree canopy evaporation. $E_{p}$ can also be described as the amount of water that would be removed through ET if the water table was at the ground surface. The

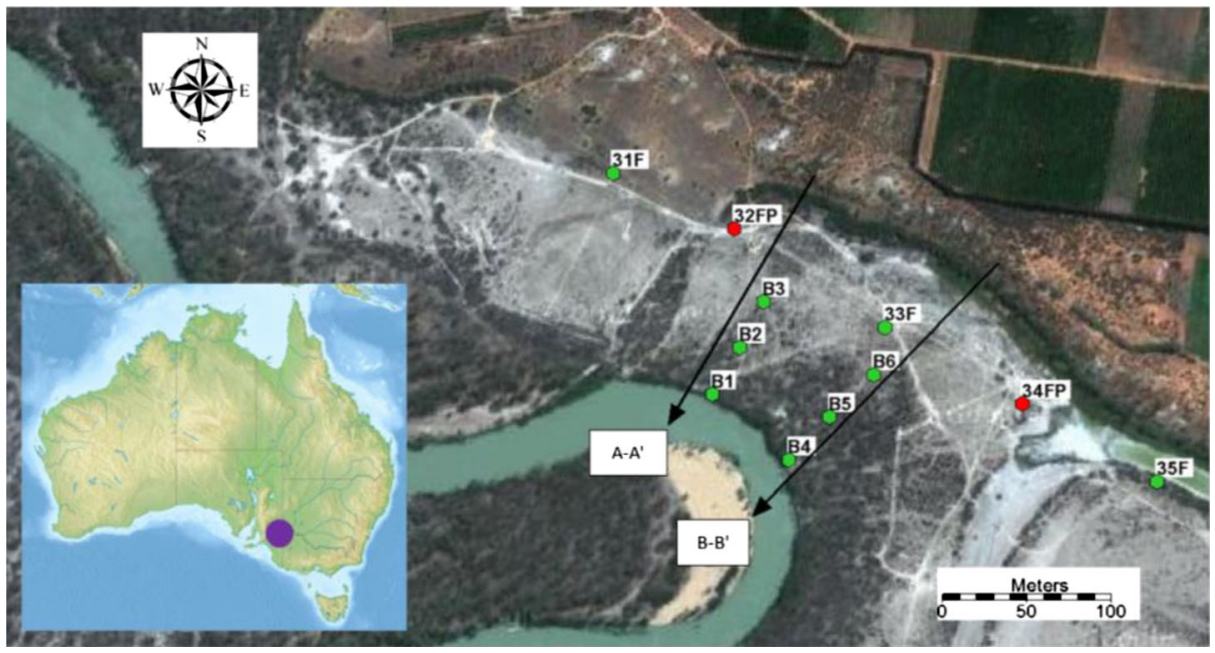

Fig. 2 Configuration of production wells (in red) and observation wells (in green) at Clark's Floodplain. The insert map shows the location of the study site in Australia (red circle) 
value and description of $E_{p}$ has followed the notation and conceptualization of Therrien et al. (2010) and Kristensen and Jensen (1975). The vegetation function $\left(f_{1}\right)$ correlates the transpiration $\left(T_{p}\right)$ with the leaf area index (LAI) in a linear fashion and the moisture content $(\theta)$ function $\left(f_{2}\right)$ correlates $T_{p}$ with the moisture state at the roots. The root zone distribution function $(\mathrm{RDF})$ is defined by $\mathrm{Eq} 2$ :

$$
\mathrm{RDF}=\frac{\int_{c 1}^{c 2} r F(z) d z}{\int_{0}^{L r} r F(z) d z}
$$

where $c 1$ and $c 2$ are dimensionless fitting parameters, $L_{r}$ is the effective root length, $\mathrm{z}$ is the depth coordinate from the soil surface [L] and $r F(z)$ is the root extraction function, which typically varies logarithmically with depth. Below the wilting point moisture content, transpiration is 0 ; transpiration then increases to a maximum at the field capacity moisture content. This maximum is maintained up to the oxic moisture content, beyond which the transpiration decreases to 0 at the anoxic moisture content. When available moisture is larger than the anoxic moisture content, the roots become inactive due to lack of aeration (Therrien et al. 2010).

In HGS, evaporation from the soil surface and subsurface soil layers is a function of nodal water content and an evaporation distribution function (EDF) over a prescribed extinction depth. The model assumes that evaporation $\left(E_{s}\right)$ occurs along with transpiration, resulting from energy that penetrates the vegetation cover and is expressed as (Therrien et al. 2010):

$$
E_{s}=\alpha\left(E_{p}-E_{c a n}\right)\left[1-f_{1}(\mathrm{LAI})\right] \mathrm{EDF}
$$

where $\alpha$ is a wetness factor which depends on the moisture content at the end of the energylimiting stage and below which evaporation is 0 . For further details on the code the reader is referred to Therrien et al. (2010).

\subsection{Study Site}

Clark's Floodplain is located on the Lower Murray River in South Australia (34 $\left.21^{\prime} \mathrm{S}, 140^{\circ} 37^{\prime} \mathrm{E}\right)$ (Fig. 2). The climate in this region is semi-arid with mild winters and long hot summers. Annual potential evaporation $(1900 \mathrm{~mm})$ is over seven times the average annual rainfall $(251 \mathrm{~mm})$. Annual rainfall is highly variable, with Bureau of Meteorology records showing annual rainfall between 86.6 and $555.8 \mathrm{~mm}$ since 1963. Annual rainfall was average or below average over the study period (165.8 mm in 2006 and $223.8 \mathrm{~mm}$ in 2007). The Lower Murray River floodplain is characterised by a flat, wide, meandering river within a deep river valley, excised during the Pleistocene period (Twidale et al. 1978). The hydrogeology of Clark's Floodplain is typical of the eastern part of the Lower Murray River (Jarwal et al. 1996). In terms of soils, Coonambidgal Clay, ranging from 2 to $7 \mathrm{~m}$ thick, covers a Monoman Formation (sand) on the floodplain. Also, Upper Loxton Sand exists on the adjacent highland. Groundwater salinity in the Loxton Sands and Monoman Formation is in excess of $30,000 \mathrm{mg} \mathrm{L}^{-1}$, while irrigation recharge salinity is typically $5,000 \mathrm{mg} \mathrm{L}^{-1}$ (Doble et al. 2006).

Two SIS production wells are located in the study site. They pump the saline groundwater at a rate of $2-3 \mathrm{~L} / \mathrm{s}$ (Fig. 2). These were in operation during the study period except for the period from November 2006 until May 2007 due to a fault in the disposal pipeline. Figure 2 shows the configuration of the nine groundwater observation wells at the study site. Six of these are located along two transects dissecting the floodplain laterally; B1, B2 and B3 on Transect A-A' and B4, B5 and B6 on Transect B-B'. In addition, SIS observation wells (31 F, $33 \mathrm{~F}$ and $35 \mathrm{~F}$ ) are located at the mid-point between the SIS production wells. The observation 
wells are designed to monitor both groundwater level and salinity. In addition, observed water levels and flows of the Murray River at the study site were obtained from the Lock 4 water level station just upstream of the study site, which has continuous data from 1927 (ID: A4260515) (WaterConnect 2012).

\subsection{Numerical Model Set-Up}

Available LiDAR data was used to generate the $10 \mathrm{~m}$ resolution Digital Elevation Model (DEM) of the study site. The three dimensional geometry grid of the study site consisted of 15 sub-layers including finer grids at the top of the model. The final geometric grid contained 104,408 nodes that formed 190,335 elements. A part of Clark's floodplain from the floodplain slope break to the Murray River main channel is included in the geometric grid. This included two SIS production wells ( $32 \mathrm{~F}$ and $34 \mathrm{~F}$ ) and nine observation wells. In this case, the length of the river bank was $570 \mathrm{~m}$ and the distance from the river bank to the SIS well varied between $480 \mathrm{~m}$ and $650 \mathrm{~m}$. The heterogeneous model domain consisted of three soil layers and was constructed according to drill log data. The $10 \mathrm{~m}$ thick Monoman Formation Sand was overlaid by spatially variable semi-confining heavy Coonambidgal Clay and also Upper Loxton Sand at the highland (Fig. 3b). The properties of the soil and unsaturated van
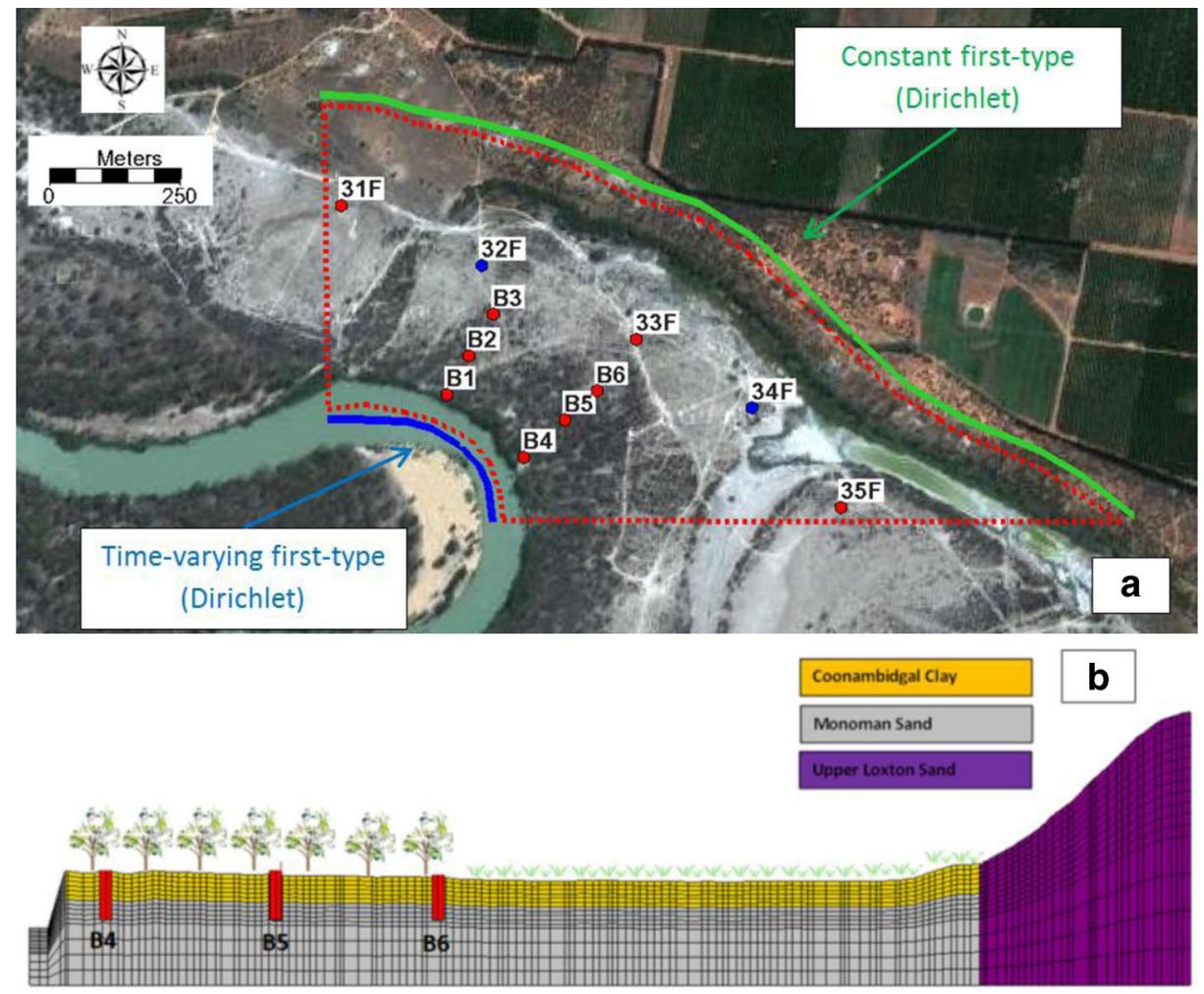

Fig. 3 a Configuration of the model boundary condition (model perimeter is shown in red dotted line); b Configuration of the vegetation and soil layers of Clark's Floodplain along Transect B-B' (Z magnification $=3$ ). Observation wells are shown in red columns 
Genuchten function parameters (van Genuchten 1980) are adopted from Jolly et al. (1993), Doble et al. (2006) and Alaghmand et al. (2013a) (Table 1).

The initial model was a transient model set up for 10,000 days to create the equilibrium initial conditions for the study period (1/1/2006 to 1/09/2010). It used an initial time step of 0.1 days, a maximum time step of 1 day and a maximum time step multiplier of 1.25 . The initial conditions of the model were determined numerically from a steady-state model run under current vegetation cover. The generated initial model was verified using the recorded groundwater heads and salinity at the beginning of the study period (January 2006), which were adopted from Berens et al. (2009).

Boundary conditions were defined for both the surface and sub-surface domains (Fig. 3a). A constant first type (Dirichlet) boundary condition was specified at the north-eastern part of the floodplain to represent the $12 \mathrm{~m}$ AHD (Australian Height Datum) groundwater head, which was adopted from AWE potentiometric contours (AWE 2013). In addition, at the river boundary of the model, a time-varying Dirichlet condition was specified which was based upon river level observations from downstream of Lock 4. Also, the observed groundwater concentration at the observation wells in the floodplain and river were characterized by the solute boundary conditions using first-type (Dirichlet) or constant concentration boundary conditions. The salinity for the floodplain groundwater was $30,000 \mathrm{mg} \mathrm{L}^{-1}$ (TDS) and river water $200 \mathrm{mg} \mathrm{L}^{-1}$ (TDS). Hence, constant values were applied at the porous media boundary (representing the regional saline aquifer) and at the river nodes. In addition, ET and rainfall were simulated for the entire model surface domain using the time-varying second-type (Neumann) boundary condition. In fact, ET was dynamically simulated as a combination of evaporation (Eq. 3) and transpiration (Eq. 1) processes by removing water from all model cells of the surface and subsurface flow domains within the defined zone of the evaporation and root extinction depths. To simulate the different vegetation covers, the transpiration process was manipulated by changing the root extinction depth and LAI. The daily reference potential evapotranspiration $\left(E_{p}\right)$ rate (in Eqs. 1 and 3) and rainfall were based upon the recorded daily values at Loxton station (ID: 024024) (BOM 2013). The parameter values for the ET components of the model are adopted from Doody et al. (2009), Hingston et al. (1997), Banks et al. (2011), Verstrepen (2011) and Alaghmand et al. (2013a) (Table 2).

Table 1 Soil parameter values of the model for the study site

\begin{tabular}{|c|c|c|c|c|}
\hline \multirow[t]{2}{*}{ Model parameter } & \multicolumn{3}{|l|}{ Value } & \multirow[t]{2}{*}{ Units } \\
\hline & Monoman Sand & Upper Loxton Sand & Coonambidgal Clay & \\
\hline Porosity & 35.0 & 45.0 & 60.0 & $\%$ \\
\hline Hydraulic conductivity & 20.0 & 10 & 0.1 & $\mathrm{~m} \mathrm{~d}^{-1}$ \\
\hline Specific storage & $1.6 \times 10^{-4}$ & $1.0 \times 10^{-4}$ & $2.0 \times 10^{-3}$ & $\mathrm{~m}^{-1}$ \\
\hline Residual water content & 0.04 & 0.04 & 0.04 & \\
\hline Evaporation limiting saturation (min) & 0.05 & 0.15 & 0.25 & \\
\hline Evaporation limiting saturation (max) & 0.9 & 0.9 & 0.9 & \\
\hline Longitudinal dispersivity & 5.0 & 5.0 & 5.0 & $\mathrm{~m}$ \\
\hline Transverse dispersivity & 0.5 & 0.5 & 0.5 & $\mathrm{~m}$ \\
\hline van Genuchten alpha parameter & 1.69 & 0.80 & 0.28 & $\mathrm{~m}^{-1}$ \\
\hline van Genuchten beta parameter & 8.25 & 3.60 & 2.52 & \\
\hline
\end{tabular}


Table 2 ET parameter values of the model for the study site

\begin{tabular}{|c|c|c|c|}
\hline \multirow[t]{2}{*}{ Model parameter } & \multicolumn{2}{|l|}{ Value } & \multirow[t]{2}{*}{ Units } \\
\hline & Eucalyptus & Grass & \\
\hline Tree canopy evaporation & $4.5 \times 10^{-4}$ & $4.0 \times 10^{-4}$ & $\mathrm{~m}$ \\
\hline $\begin{array}{l}\text { Evaporation extinction depth defined by quadratic decay Evaporation } \\
\text { distribution function }\end{array}$ & 1 & 1 & $\mathrm{~m}$ \\
\hline $\begin{array}{l}\text { Transpiration extinction depth defined by quadratic decay Root } \\
\text { distribution function }\end{array}$ & 5.0 & 0.5 & $\mathrm{~m}$ \\
\hline Leaf area index & 1.5 & 0.5 & $\mathrm{~m}^{2} \mathrm{~m}^{-2}$ \\
\hline Transpiration fitting parameter $\mathrm{c} 1$ & 0.3 & 0.6 & \\
\hline Transpiration fitting parameter $\mathrm{c} 2$ & 0.2 & 0.0 & \\
\hline Transpiration fitting parameter $\mathrm{c} 3$ & 1.0 & 1.0 & \\
\hline Transpiration limiting saturation (at wilting point) & 0.29 & 0.29 & \\
\hline Transpiration limiting saturation (at field capacity) & 0.56 & 0.56 & \\
\hline Transpiration limiting saturation (at oxic limit) & 0.85 & 0.75 & \\
\hline Transpiration limiting saturation (at anoxic limit) & 0.95 & 0.90 & \\
\hline
\end{tabular}

\subsection{Model Calibration}

Observed groundwater levels and salinity at the six observation wells were used as calibration criteria during coupled flow-and-transport calibration of the model. Calibration of the model was conducted manually with more consideration given to sensitive parameters such as soil hydraulic conductivity, porosity and transverse and longitudinal dispersivity. Two different approaches were used to calibrate the model in terms of flow and solute dynamics. The model performance for flow dynamics was tested both quantitatively and qualitatively. The former was performed using goodness-of-fit parameters which produced averages of 0.88 and $0.08(\mathrm{~m})$ for $\mathrm{R}^{2}$ and RMSE, respectively. Also, visual comparison between the observed and simulated series of groundwater levels at the observation wells showed that the calibrated model was able to reproduce the SW-GW interaction processes in an acceptable manner. On the other hand, due to the difficulty associated with the quantification of the solute transport model parameters and lack of accurate estimations of the thickness, hydraulic conductivity and porosity of the aquifer, the solute dynamic was calibrated based on the observed concentration patterns. Hence, the modelled solute concentration distributions were compared visually to electromagnetic survey results reported by Berens et al. (2009). For instance, the EM31 survey in November 2007 displays a distinct zone of low conductivity along the eastern margin abutting the river channel (Berens et al. 2009). A detailed description of the calibration process can be found in Alaghmand et al. (2013a).

\section{Results and Discussion}

To investigate the impacts of vegetation cover on the dynamics of flow and solute, three scenarios were defined and modelled. The dynamics of flow in the defined scenarios are discussed based on ET, evaporation, bank recharge (flux from the river to the floodplain aquifer) and GW heads. Figure 4 shows the total amount of water removed from the floodplain aquifer through ET and evaporation during the study period. The seasonal trends in both are 

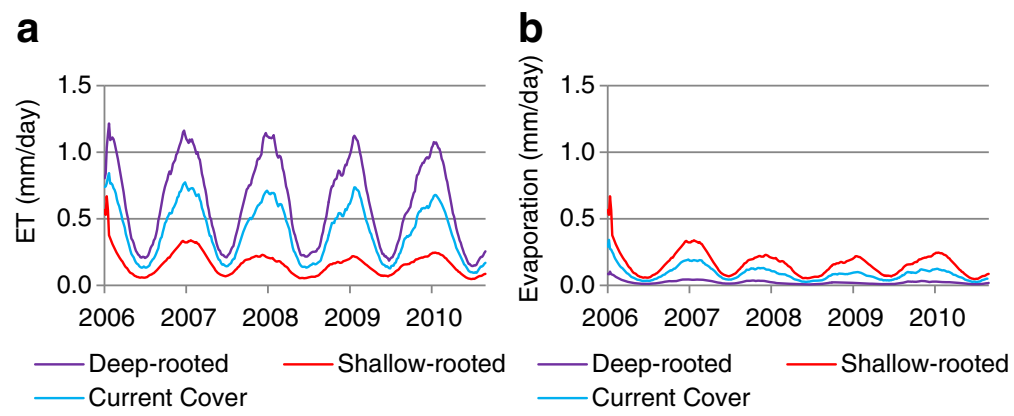

Fig. 4 ET (a) and evaporation only (b) during the study period for the defined scenarios

obvious. However, among the simulated scenarios, the deep-rooted model shows the highest amount of ET. This is due to the deeper root depths and LAI values which were assigned for the deep-rooted model. Clearly, vegetation with deeper roots and higher canopies use larger amounts of water. Doble et al. (2006) suggested 180-360 mm/year for the eucalyptus (red gum) and $0-40 \mathrm{~mm} / \mathrm{year}$ for the grassland in this area. The results show that ET is more pronounced during the summer period compared to winter, as both transpiration and evaporation occurs with higher rates in summer. Figure $4 \mathrm{~b}$ shows the amount of water removed from the system only through evaporation (with no transpiration). Shallow-rooted floodplain vegetation shows increased losses via evaporation. Considering the assigned evaporation depth $(1 \mathrm{~m})$ and transpiration depth $(0.5 \mathrm{~m})$, most of the ET component in this scenario belongs to the evaporation process, as the groundwater depth was unlikely to be less than $0.5 \mathrm{~m}$. Furthermore, in the shallow-rooted vegetation cover, the water table is shallower compared to the deeprooted vegetation. Hence, more groundwater is exposed to be evaporated. On the other hand, the deep-rooted model uptakes the groundwater via a transpiration process and consequently keeps groundwater levels below the evaporation depth $(1 \mathrm{~m})$. Therefore, Fig. 4b shows the lowest evaporation for this scenario.

Figure 5 illustrates the impacts of floodplain vegetation cover on the water flow exchange between the river and the floodplain aquifer. This shows the cumulative bank recharge during the study period for the defined scenarios. In fact, it represents the amount of water moved from the river (surface domain) to the floodplain aquifer (sub-surface domain). As expected, more water moves to the floodplain aquifer from the river in the deep-rooted model. In other words, the floodplain aquifer with deep-rooted vegetation cover consumes more water through ET compared to that with shallow-rooted vegetation. Also, when a floodplain is covered with deep-rooted vegetation, a deeper water table is formed. Hence, this can form a hydraulic gradient from the river towards the floodplain aquifer or at least it can decrease the hydraulic gradient from the aquifer to the river. While, in the case of the shallow-rooted vegetation cover, there is a shallower water table which creates less cumulative bank recharge.

As discussed previously, the role of trees as groundwater pumps and their potential impacts on exchange fluxes between SW and GW is clear in the literature (Banks et al. 2011; Brunner et al. 2009; Butler et al. 2007; Loheide et al. 2005). However, this study was able to show this in a quantitative way, as it is shown here that ET can significantly influence the SW-GW interaction, for both water and solute. Banks et al. (2011) showed that deep-rooted vegetation (with high ET) has the potential to maintain a lower elevation of the water table in the floodplain aquifer. Figure 6 shows the dynamics of GW hydraulic heads along Transect B-B ' (observation wells BO4, BO5 and BO6; Fig. 2) during the study period for the defined scenarios. It appears that floodplain vegetation cover changes did not produce any significant 


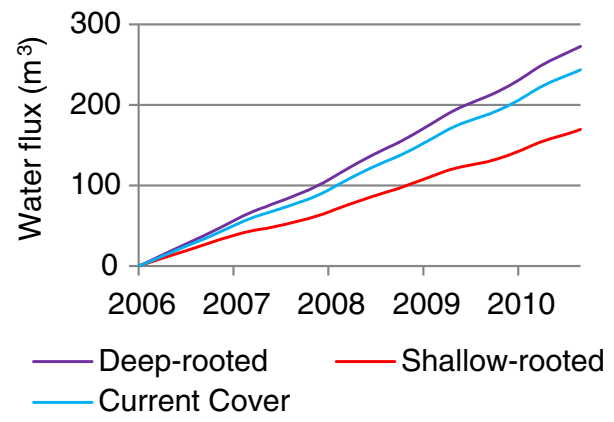

Fig. 5 Cumulative river bank recharge during the study period for the defined scenarios

changes in GW heads around the river bank (observation well BO4). This may be due to good connectivity between the river and the floodplain aquifer. This is because of the relatively high hydraulic conductivity at the river bank. But at observation wells BO5 and BO6 the influence of vegetation cover on GW heads are significant. These impacts are consistent with the results in Fig. 4, as more water use is expected in a deep-rooted covered floodplain. In fact, deep-rooted vegetation cover is able to maintain a lower water table compared to shallow-rooted vegetation cover. It is worth noting that in this investigation, the vegetation cover was not able to change the state of connection between the river and floodplain to any extent. This is because of a lack of a clogging layer between the river and the floodplain aquifer.
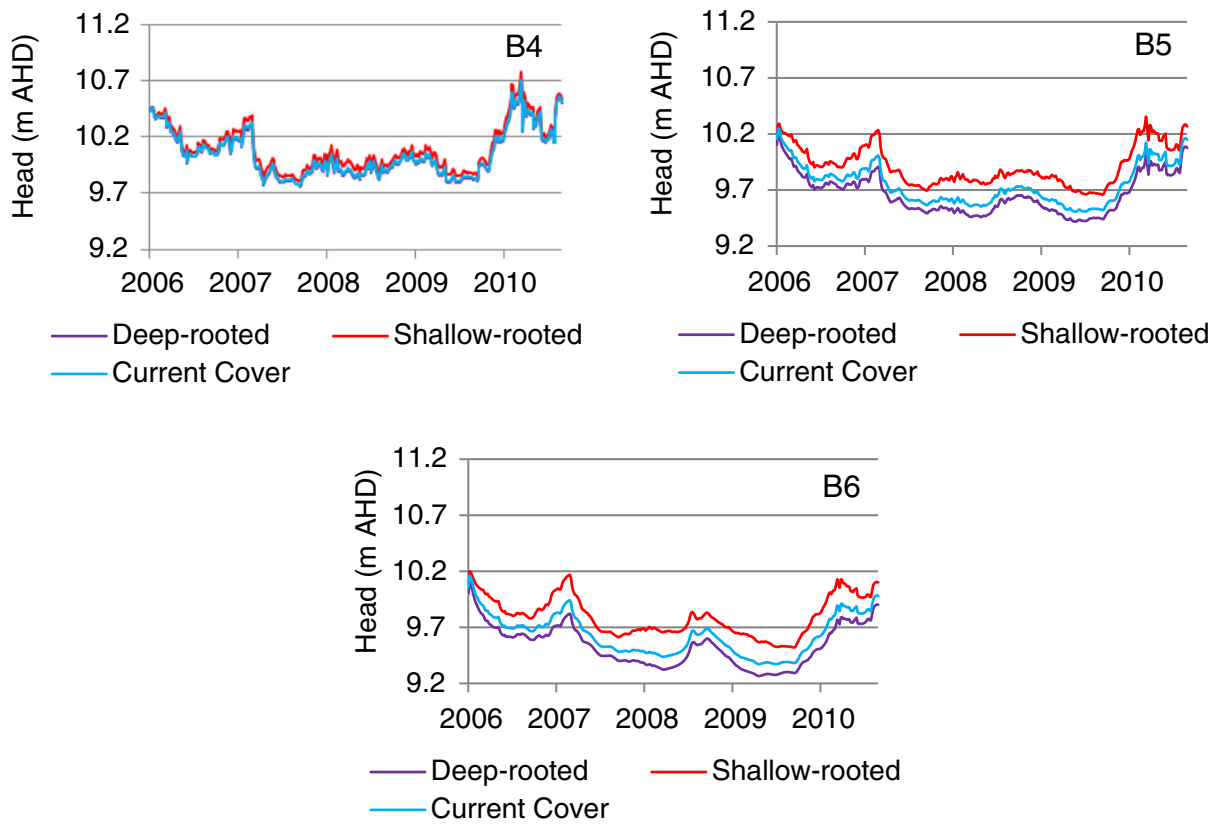

Fig. $6 \mathrm{GW}$ head dynamics along Transect B-B' (BO4, BO5 and BO6) during the study period for the defined scenarios 


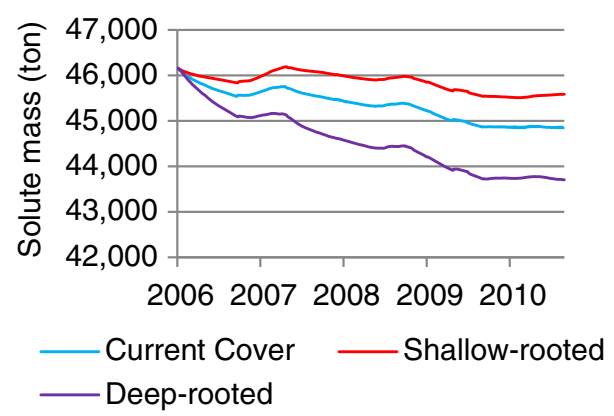

Fig. 7 Total solute mass in the system at each time step for the defined scenarios

In such a semi-arid floodplain where recharge from rainfall never happens (due to high evaporation rates compared to rainfall), the floodplain aquifer recharge is limited to the river via bank recharge or saline groundwater recharge from the highland aquifer or through agricultural drainage. Hence, any driver that influences the flow recharges to the system, eventually influences the solute dynamics of the system as well. In terms of solute dynamics, the amount of solute mass in the system at each time step is illustrated in Fig. 7. As shown in Fig. 7, the amount of solute in the system decreases during all scenarios. This is because of operation of the groundwater extraction via the SIS production wells during the study period. In fact, all the results of this study are influenced by groundwater extraction. When the SIS production wells were in operation the salt mass accumulation was decreasing. But, during the SIS shutdown period, a slight increase in solute mass accumulation can be observed in Fig. 7. However, the shallow-rooted vegetation cover model shows relatively more solute mass in the system. This is clearly due to the raised water table, which increases saline groundwater recharge from the saline high land aquifer. According to the results of this study, a floodplain with deep-rooted vegetation forms a less saline floodplain aquifer. In other words, for each time step, less solute accumulates in the system. To support this, Fig. 8 shows the cumulative solute mass stored in the system during the study period for the defined scenarios. Clearly, vegetation cover with deeper roots is able to comparatively mitigate solute accumulation in the floodplain aquifer by keeping the saline groundwater table relatively lower compared to shallow rooted vegetation.

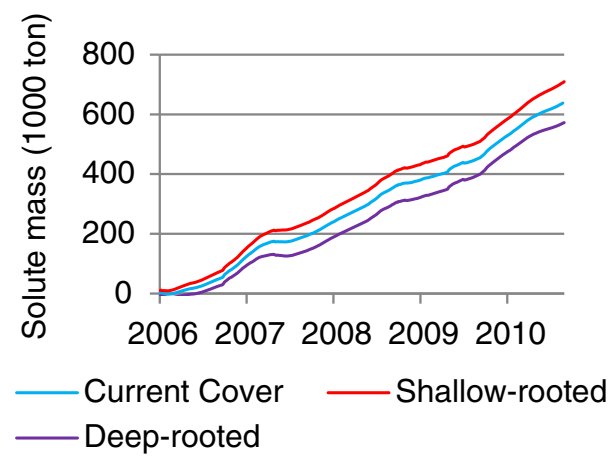

Fig. 8 Cumulative solute mass stored in the system during the study period for the defined scenarios 


\section{Conclusions}

The potential impacts of vegetation cover on the interaction of a river and a saline semi-arid floodplain aquifer has been investigated quantitatively. To this end, a three-dimensional physically-based fully integrated numerical model was developed and calibrated. Clark's Floodplain located on the Lower Murray River in South Australia was selected as the study site. This site was influenced by GW extraction from a Salt Interception Scheme. The results of numerical modelling of three defined scenarios showed that deep-rooted vegetation cover may maintain a deeper water table. This is because more water is removed from the system through ET. Deep-rooted vegetation has deeper root depths and higher LAI, resulting in more water uptake compared to shallow-rooted vegetation. In fact, the main component of the groundwater ET belongs to a transpiration process as the groundwater level is maintained below the evaporation depth in the deep-rooted scenario. However, shallow-rooted vegetation cover led to higher evaporation rates because a shallower water table makes more water available for evaporation from the soil. Furthermore, in terms of solute dynamics, due to increased GW recharge and raised water tables, shallow-rooted vegetation formed a relatively more saline floodplain aquifer. In this case study, vegetation cover did not influence the river-floodplain connectivity due to the lack of a clogging layer at the river bank. Overall, vegetation cover type can have significant impacts on the flow and solute dynamics of interactions between a river and a floodplain aquifer in a semi-arid area, because ET is one of the dominant hydrological drivers.

Acknowledgments An initial version of this paper was presented at the 8th International Conference of the EWRA in Porto, Portugal, June 26-29, 2013.

\section{References}

Alaghmand S, Beecham S, Hassanli A (2013a) Impacts of groundwater extraction on salinization risk in a semiarid floodplain. Natural Hazards and Earth System Sciences in press (nhess-2013-167)

Alaghmand S, Beecham S, Hassanli A (2013b) A review of the numerical modelling of salt mobilization from groundwater-surface water interactions. Water Resour 40(3):325-341

Alexander HD, Dunton KH (2006) Treated wastewater effluent as an alternative freshwater source in a hypersaline salt marsh: impacts on salinity, inorganic nitrogen, and emergent vegetation. J Coast Res 22(2):377-392

Allison GB, Cook PG, Barnett SR, Walker GR, Jolly ID, Hughes MW (1990) Land clearance and river salinisation in the western Murray Basin, Australia. J Hydrol 119(1-4):1-20. doi:10.1016/0022-1694(90)90030-2

AquaVeo (2011) Groundwater modelling system. Provo, U.S

AWE (2013) Loxton Bookpurnong SIS Atlas. Australian Water Environment, Adelaide

Banks EW, Brunner P, Simmons CT (2011) Vegetation controls on variably saturated processes between surface water and groundwater and their impact on the state of connection. Water Resour Res 47(11)

Berens V, White M, Souter N (2009) Bookpurnong Living Murray Pilot Project: A trial of three floodplain water management techniques to improve vegetation condition. Department of Water, Land and Biodiversity Conservation, Adelaide

BOM (2013) Bureau of Meteorology (BOM)., http://www.bom.gov.au

Bornman TG, Adams JB, Bate GC (2004) The influence of floodplain geohydrology on the distribution of Sarcocornia pillansii in the Olifants Estuary on the West Coast, South Africa. J Arid Environ 56(4):603-625

Brunner P, Simmons CT, Cook PG (2009) Spatial and temporal aspects of the transition from connection to disconnection between rivers, lakes and groundwater. J Hydrol 376(1-2):159-169

Butler JJ, Kluitenberg GJ, Whittemore DO, Loheide SP, Jin W, Billinger MA, Zhan X (2007) A field investigation of phreatophyte-induced fluctuations in the water table. Water Resour Res 43(2), W02404. doi:10.1029/2005wr004627

Capon SJ (2005) Flood variability and spatial variation in plant community composition and structure on a large arid floodplain. J Arid Environ 60(2):283-302 
Doble R, Simmons C, Jolly I, Walker G (2006) Spatial relationships between vegetation cover and irrigationinduced groundwater discharge on a semi-arid floodplain, Australia. J Hydrol 329(1-2):75-97. doi:10.1016/ j.jhydrol.2006.02.007

Doody TM, Holland KL, Benyon RG, Jolly ID (2009) Effect of groundwater freshening on riparian vegetation water balance. Hydrol Process 23(24):3485-3499

Evans R (2011) Flood-plain salt storage - conceptualisation of its movement. Paper presented at the Murray Darling Basin Authority - Basin Salinity Management Strategy A Targeted Workshop on Flood Recession Salinity Investigation, Canberra

Hingston FJ, Galbraith JH, Dimmock GM (1997) Application of the process-based model BIOMASS to eucalyptus globules subsp. Globules plantations on ex-farmland in south Western Australia: I. Water use by trees and assessing risk of losses due to drought. For Ecol Manage 106:141-156

Holland KL, Jolly ID, Overton IC, Walker GR (2009) Analytical model of salinity risk from groundwater discharge in semi-arid, lowland floodplains. Hydrol Process 23:3428-3439

Jarwal SD, Walker GR, Jolly ID (1996) General site description; Salt and Water Movement in the Chowilla Floodplain. CSIRO Division of Water Resources

Jolly ID, Walker GR, Thorburn PJ (1993) Salt accumulation in semi-arid floodplain soils with implications for forest health. J Hydrol 150(2-4):589-614. doi:10.1016/0022-1694(93)90127-u

Kristensen KJ, Jensen SE (1975) A model for estimating actual evapotranspiration from potential evapotranspiration. Nord Hydrol 6(3)

Leblanc M, Tweed S, Van Dijk A, Timbal B (2012) A review of historic and future hydrological changes in the Murray-Darling Basin. Global Planet Change 80-81:226-246

Loheide SP, Butler JJ, Gorelick SM (2005) Estimation of groundwater consumption by phreatophytes using diurnal water table fluctuations: a saturated-unsaturated flow assessment. Water Resour Res 41(7), W07030. doi: $10.1029 / 2005 \mathrm{wr} 003942$

Mensforth LJ, Walker GR (1996) Root dynamics of Melaleuca halmaturorum in response to fluctuating saline groundwater. Plant and Soil 184(1):75-84

Rassam DW (2002) Variation of evaporative and shear strength parameters along a tailings delta. Can Geotech J 39(1):32-45

Rassam DW (2011) A conceptual framework for incorporating surface-groundwater interactions into a river operation-planning model. Environ Model Software 26(12):1554-1567. doi:10.1016/j.envsoft.2011.07.019

River Murray Water Data (2012) https://www.waterconnect.sa.gov.au/RMWD/Pages/default.aspx

Rosenberry DO, Winter TC (1997) Dynamics of water-table fluctuation in an upland between two prairie potholes wetlands in North Dakota. J Hydrol 191:266-289

Therrien R, McLaren RG, Sudicky EA, Panday SM (2010) HydroGeoSphere: A three-dimensional numerical model describing fully-integrated subsurface and surface flow and solute transport. Code Documentation and User's Guide. Groundwater Simulations Group, University of Waterloo, Waterloo, Canada

Twidale CR, Lindsay JM, Bourne JA (1978) Age and origin of the Murray River and gorge in South Australia. Paper presented at the The Royal Society of Victoria 90

van Genuchten MT (1980) A closed-form equation for predicting the hydraulic conductivity of unsaturated soils. Sci Soc Am J 44(5):892-898

Verstrepen L (2011) Evaluating rainwater harvesting on watershed level in the semi-arid zone of Chile. Universiteit Gent 